\title{
ПСИХОЛОГИЧЕСКИЕ ОСОБЕННОСТИ СОЦИАЛЬНО- ПСИХОЛОГИЧЕСКИХ УСТАНОВОК В СТРУКТУРЕ ЦЕННОСТНО-СМЫСЛОВОЙ СФЕРЫ ЛИЧНОСТИ С РАЗЛИЧНЫМИ УРОВНЯМИ ИНТЕРНЕТ-АКТИВНОСТИ
}

\section{PSYCHOLOGICAL FEATURES OF SOCIO- PSYCHOLOGICAL ATTITUDES IN THE VALUE-SENSE SPHERE'S STRUCTURE OF A PERSONALITY WITH DIFFERENT LEVELS OF INTERNET ACTIVITY}

\section{R. Zekeryaev}

Summary: In this article presented the analysis' results of scientific literature research devoted to the study of the value-semantic sphere; described the psychological characteristics of socio-psychological attitudes in the structure of the value-semantic sphere of the individual; revealed the essence of a number of socio-psychological attitudes such as orientation to the process, orientation to the result, orientation to altruism, orientation to egoism, orientation to work, orientation to money, orientation to freedom, orientation to power; presented analysis' results of study of the person's Internet activity level's influence on the psychological characteristics a person's socio-psychological attitudes.

Keywords: value-semantic sphere of personality, socio-psychological attitudes, goals in life, life process, life performance, external locus of control, internal locus of control, Internet activity.

\section{Введение}

$\mathrm{H}$ а данном этапе развития научной мысли изучение особенностей процесса формирования ценностно-смысловой сферы личности представляет собой актуальную проблему в психологической науке. Принято считать, что основными факторами, детерминирующими психологические особенности конструирования системы ценностей и смыслов, является процесс социализации личности в процессе ее развития. Необходимо также отметить, что ценностно-смысловая сфера, выступая ядром в структуре личности, определяет ее направленность, регулирует ее социальное поведение, а также находится в непрерывном развитии. Ценностные и смысловые образования обладают характером динамичности и неустойчивости, модифицируясь и адаптируясь под влиянием внешних условий, окружающего социума, условий деятельности и т.д. Значительные изменения психологических особенностей формирования ценностно-смысловой сферы личности начали возникать с внедрением в человеческую жизнь сети Интер-
Зекерьяев Руслан Ильвисович

Преподаватель, ГБОУ ВО Республики Крым «Крымский инженерно-педагогический университет» ruslan51291@mail.ru

Аннотация: В статье представлены результаты анализа научно-исследовательской литературы, посвященной изучению ценностно-смысловой сферы личности; описаны психологические особенности социально-психологических установок в структуре ценностно-смысловой сферы личности; раскрыта сущность ряда социально-психологических установок, таких как ориентация на процесс, ориентация на результат, ориентация на альтруизм, ориентация на эгоизм, ориентация на труд, ориентация на деньги, ориентация на свободу, ориентация на власть; представлен анализ исследования влияния уровня интернет-активности личности на психологические особенности социальнопсихологических установок личности.

Ключевые слова: ценностно-смысловая сфера личности, социально-психологические установки, ориентация на процесс, ориентация на результат, ориентация на альтруизм, ориентация на эгоизм, ориентация на труд, ориентация на деньги, ориентация на свободу, ориентация на власть, интернет-активность.

нет. Система гиперреальности, которая выступает еще одним институтом социализации, является носителем социальных и культурных норм и ценностей. Входя в виртуальную среду сети Интернет, человек перенимает ее навязываемые ею нормы, ценностные ориентации, личностные смыслы, интернализируя их в свою ценностно-смысловую сферу, в частности в систему социально-психологических установок личности. При этом остаются открытыми вопросы, связанные с психологическими особенностями влияния процесса интернет-социализации личности на систему личностных ценностей и смыслов.

Целью статьи является анализ результатов исследования психологических особенностей социально-психологических установок в структуре ценностно-смысловой сферы личности с различными уровнями интернет-активности.

Основное изложение материала. 
В психологии под ценностно-смысловой сферой личности понимается сложный комплекс ее норм и убеждений, мотивационных особенностей, мировоззрения, целей, социальных установок под влиянием социокультурной среды, в которой она вступает в социальное взаимодействие. Смысловые и ценностные ориентации при этом выступают в качестве регулятора поведения человека и основы для принятия им решений.

Анализ системы ценностей и смыслов позволяет определить, что она включает в себя психологические особенности осознания личностью своего субъективного внутреннего мира и внешней объективной реальности. Ценностно-смысловая сфера является комплексом характеристик, таких как субъективность (основанная на личном опыте), осознанность, комплексность, иерархичность и т.д. Эти свойства детерминируют особенности ее динамики с помощью ряда таких механизмов, как рефлексия, интернализация, экстернализация, индивидуализация, адаптация и т.д. При этом ценностно-смысловая сфера выступает в роли личностного конструкта, который определяет характер внутренних социокультурных ориентиров на определенный образ жизни.

Процесс формирования и трансформации системы ценностей и смыслов детерминировано взаимосвязью внутренних субъективных и внешних объективных процессов. При этом наблюдается перманентная динамика как личностных ценностных образований, так и социальных смыслов и ценностей. Изменение ценностно-смысловой сферы является внутренним стремлением личности к определенному стилю жизнедеятельности, каким-либо целям и перспективам. Также оно обуславливает выбор поведенческих паттернов в процессе социального взаимодействия и деятельности, что детерминирует психологические особенности саморегуляции системы отношений личности к себе и своей жизни. Динамика развития системы ценностей и смыслов личности может рассматриваться также как внутриличностый процесс, цель которого представляет собой ценностносмысловое определение человеком себя самого в процессе своей социализации в обществе, поведения, деятельности.

Рядом ученых, исследовавших ценностно-смысловую сферу личности, была отмечена двойственность ее ценностей. С одной стороны, в ее основе лежит социальная обусловленность в виду того, что она формируется в ходе социокультурного взаимодействия человека с обществом и достижения им в нем определённого статуса. С другой стороны, в основе ценностно-смысловой сферы лежат индивидуальные особенности личности, заключающиеся в ее потребностях, направленности, интересах, поведенческих паттернах и т.д. При этом система ценностей и смыслов заключает в себе набор установок, которые интегрируясь в сознание личности, создают систему субъективного оценивания явлений объективной реальности. Исследователи так же отмечали иерархичность структуры ценностно-смысловой сферы личности, отмечая, что она представляет собой вертикаль смыслов и ценностей, упорядоченных от прагматичных и конкретно-ситуативных до экзистенциально-абстрактных $[10 ; 11]$.

Э.В. Галажинский, изучая ценностно-смысловую сферу, отмечал, что она может детерминировать процесс творческой самореализации в условиях сложившейся ситуации. По мнению ученого, развитие системы ценностей и смыслов является способом разрешения противоречий между субъективной картиной мира и реальной объективной социальной ситуацией. В данном процессе происходит также самодвижение личности, а также ее самоосуществление и самореализация. При этом Э.В. Галажинский отмечал, что характеристиками этих явлений могут выступать эмоциональная устойчивость, спонтанность, креативность, ответственность, лабильность поведенческих паттернов, чувствительность и компетентность во времени [5].

Ряд ученых в исследованиях природы ценностносмысловой сферы выделяли смыслообразование как основной фактор формирования личностных смыслов, осознанность которых зачастую имплицитна. В этом свойстве исследователи видели отличие смыслов от ценностей, которые выступают в роли базовых формирующих единиц в сознании личности. При этом личностные смысловые структуры всегда связаны с универсальными ценностями, которые определяют смысл жизни человека, а также модифицируют его интернальную и экстернальную реальность его личности. Исследователи также отмечают деятельность как специфический процесс конструирования ценностно-смысловой сферы. При этом делается особый акцент на односторонней детерминации ценностей и смыслов, при которой ценностные конструкты способствуют формированию системы смыслов личности $[2 ; 3]$.

Н.Н. Васягина, исследуя ценностно-смысловую сферу личности, особое внимание уделяла социкультурным особенностям самодетерминации человека. По ее мнению, данный процесс является неявной включенностью личности в познаваемый окружающий мир, которая также определяет факторы активности человека. При этом наблюдается взаимовлияние между системой ценностей и смыслов, принадлежащих социуму, в котором функционирует человек, и субъективных ценностных образований самой личности. Ученая также определяла, что развитие личности является двухуровневым, а также включает в себя понимание личности как субъекта социального взаимодействия и личности в проявлении ее самоидентичности. Такой подход позволяет дифференцировать факторы, формирующие личность: самосознание, базовые качества и ценностно-смысловая сфера [4]. 
Ряд исследователей объяснял феномен ценностносмысловой сферы личности как одного из элементов психики, детерминирующего отношение человека к себе самому и окружающим людям, а также выступающего в роли регулятора поведения в социуме. Ученые отмечали, что система ценностей и смыслов позволят фильтровать поступающие из окружающей среды информационные потоки, выбирая из них те, которые представляют какую-либо значимость для личности. Также, по мнению исследователей, ценностно-смысловая сфера выступает ведущим фактором, детерминирующим целеполагание и обеспечивающим процесс конструирования осмысленной и системной картины окружающего социального мира $[1 ; 8 ; 9]$.

Д.А. Леонтьев, изучая ценностно-смысловую сферу личности отмечал, что она может проявляться в трех взаимосвязанных формах. Первая из них включает в себя социокультурные ценности и представления об идеалах, сформированные общественным сознанием. Вторая проявляется в объективированном воплощении первой формы в виде результатов творческой деятельности в искусстве. Третья - является системой мотиваций личности, которая детерминирует деятельность человека с целью реализации своих целей социально-одобряемыми способами. Данные формы являются иерархичными и односторонне направленными: личность в ходе социализации интериоризирует ценности и смыслы, которые потом предметно воплощаются в результатах ее деятельности и формируют новые социальные нормы и идеалы [6].

На данном этапе развития общества, одним из факторов, детерминирующим трансформации в структуре ценностно-смысловой сферы личности является интернет-активность личности. Данное явление обусловлено тем, что система гиперреальности является одним из ведущих институтов социализации, а значит оказывает прямое влияние на систему ценностей и смыслов личности.

А.И. Лучинкина в своих исследованиях выделила 4 группы пользователей по уровню интернет-активности, которая характеризуется количеством времени, проводимом в ресурасах системы гиперреальности. К пассивным пользователям исследовательница относила людей, которые входят в виртуальное пространство не более двух раз в неделю, при этом время их пребывания там составляет менее одного часа за сессию. Деятельность таких пользователей характеризуется низким стремление к контактам с другими пользователями в виртуальных сообществах, а также отсутствием мотивации использовать сеть Интернет для поиска информации. Ученая также отмечала, что реальное пространство для пассивных пользователей обладает большей ценностью и значимостью по сравнению с виртуальным, а мотива- ция нахождения в системе гиперреальности находится на низком уровне. По мнению А.И. Лучинкиной к ситуативным пользователям можно отнести людей, которые находятся в сети Интернет ежедневно по 1-2 часа. При этом, по мнению исследовательницы, для таких людей процесс виртуального социального взаимодействия является значимым только в условиях наличия свободного времени и необходимости, но сама деятельность в системе гиперреальности отличается разнообразием и широтой используемого инструментария. А.И. Лучинкина отмечала, что активными пользователями можно считать людей, которые ежедневно проводят в виртуальной среде 3-7 часов и занимаются разнообразной деятельностью. Ученая отмечала, что для них свойственно единовременно выполнять несколько задач и находится онлайн сразу в нескольких ресурсах для общения. А.И. Лучинкина к чрезмерно-активным пользователям относила людей, которые ежедневно находятся в виртуальной среде более 7 часов, единовременно находятся на нескольких ресурсах и выполняют разные виды деятельности. По мнению исследовательницы для чрезмерноактивных пользователей характерно наделять систему гиперреальности более высокой значимостью, нежели реальное пространство [7].

В ходе исследования влияния уровня интернет-активности личности на ее ценностно-смысловую сферу приняло участие 100 человек, среди которых 50 мужчин и 50 женщин. Возрастные границы не устанавливались. Участники были привлечены с помощью рассылки приглашений к участию в исследовании.

В ходе исследования была использована методика «Диагностика социально-психологических установок личности в мотивационно-потребностной сфере» О.Ф. Потёмкиной (для определения психологических особенностей социально-психологических установок личности респондентов), а также задан вопрос о количестве времени, проводимом в сети интернет (для определения уровня интернет-активности респондентов)

В ходе анализа полученных результатов было выявлено, что в выборке оказались респонденты из каждой группы по критерию интернет-активности (рис. 1).

Далее в ходе исследования была определена степень выраженности каждой из социально-психологических установок личности.

Шкала «Ориентация на процесс» определяет степень значимости для респондента того, чтобы дело, которым он занимается, представляло для него интерес. При выраженности данной шкалы для испытуемого характерно отсутствие размышлений над целью и ее достижением, так как основное значение для него имеет непосредственно процесс выполнения работы. В случае, когда 


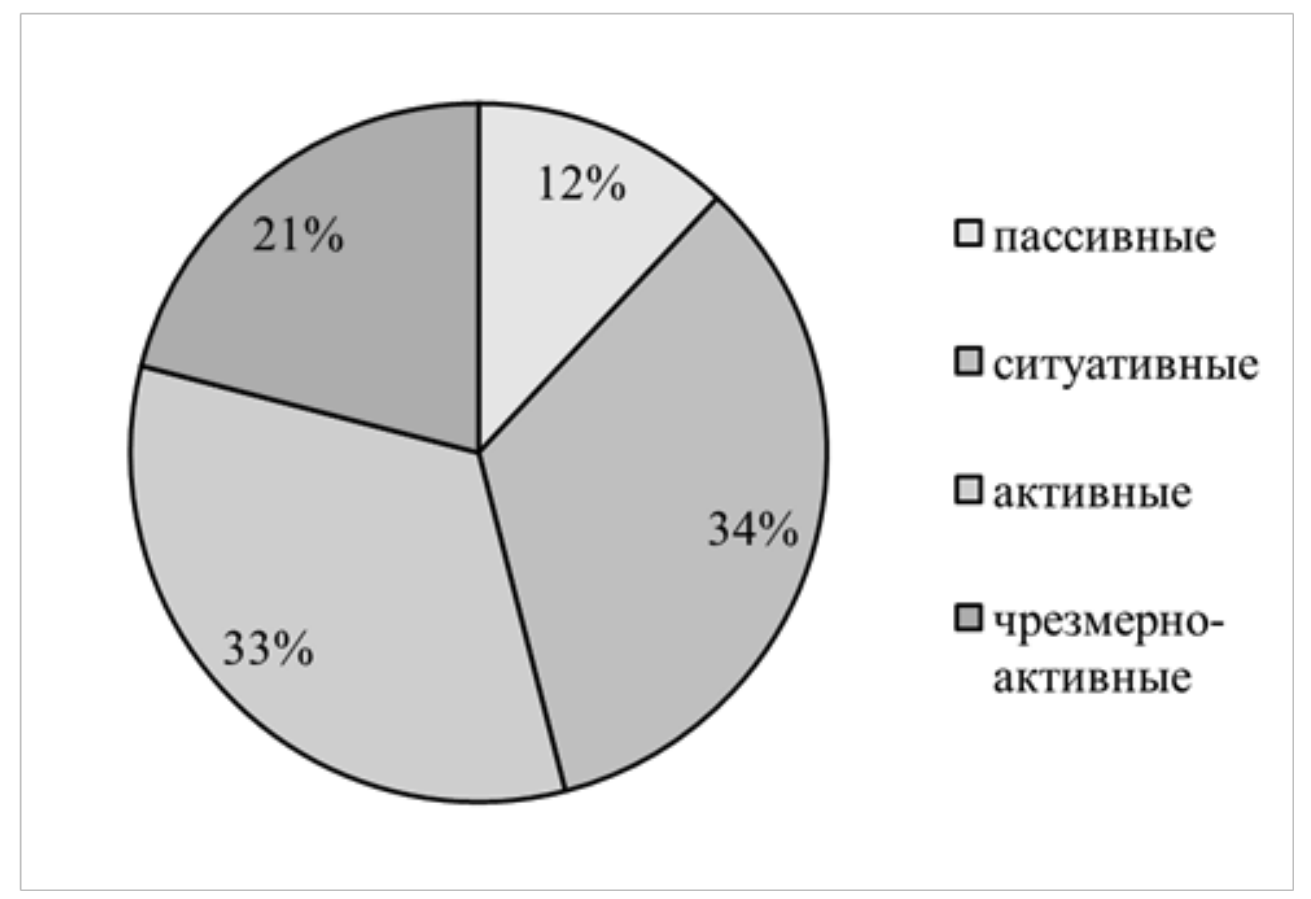

Рис. 1. Распределение респондентов по уровню интернет-активности

деятельность не представляет для респондента интерес, он склонен бросать его. Однако следует отметить, что при выраженности данной шкалы респонденту легче дается выполнение заданий, где необходима концентрация на самой работе. Также для таких испытуемых характерно предпочтение процессуальной направленности результату, так как они зачастую мотивируются именно интересом к самой деятельности, а не к ее цели.

Шкала «Ориентация на результат» определяет степень значимости цели деятельности, как социальнопсихологической установки. При высоких ее показателях для респондента важным является достижение цели работы вопреки возникающим факторам, которые затрудняют этот процесс. Однако необходимо отметить, что для таких испытуемых характерно пренебрежение «экологичностью» процесса деятельности в пользу достижения заранее намеченного результата.

Шкала «Ориентация на альтруизм» отображает степень готовности человека в работе принимать решения и совершать действия у пользу других людей, пренебрегая своими интересами. Респонденты с высокими показателями по данной шкале склонны уступать другим людям, но при этом также отмечается то, что в данном процессе они могут навязывать свое понимание и гиперболизировать значимость своих действий.

Шкала «Ориентация на эгоизм» отображает степень сосредоточенности на собственных интересах и готовность пренебречь желаниями и потребностями других людей. У респондентов с высокими показателями по данной шкале отмечается готовность в ситуации нео- пределенности действовать в согласии с собственными целями, при этом цели других людей ими зачастую сознательно игнорируются и не берутся во внимание.

Шкала «Ориентация на труд» показывает степень готовности использовать свободное время для выполнения поставленной работы, как социально-психологической установки. У респондентов с высокими показателями по данной шкале отмечается тенденция получать удовольствие от проделанной работы. При этом необходимо отметить, что результативность работы не представляет для испытуемого ценности, но для него значимо социальное одобрение его деятельности от общества. Для таких испытуемых также характерна готовность работать даже при отсутствии материальной выгоды от результатов деятельности.

Шкала «Ориентация на деньги» отображает степень выраженности стремления к улучшению собственного финансового благосостояния, как социально-психологической установки. У респондентов с высокими показателями по данной шкале отмечается высокая самоценность денег, при которой они не рассматриваются как инструмент для достижения каких-либо других целей. Также для таких испытуемых характерна мотивация высокой оплаты труда больше, чем интересом к самой деятельности.

Шкала «Ориентация на свободу» показывает степень значимости свободы, как социально-психологической установки. Для респондентов с высокими показателями по данной шкале свобода является самоценной, а ограничения любого рода воспринимаются как преграда, 


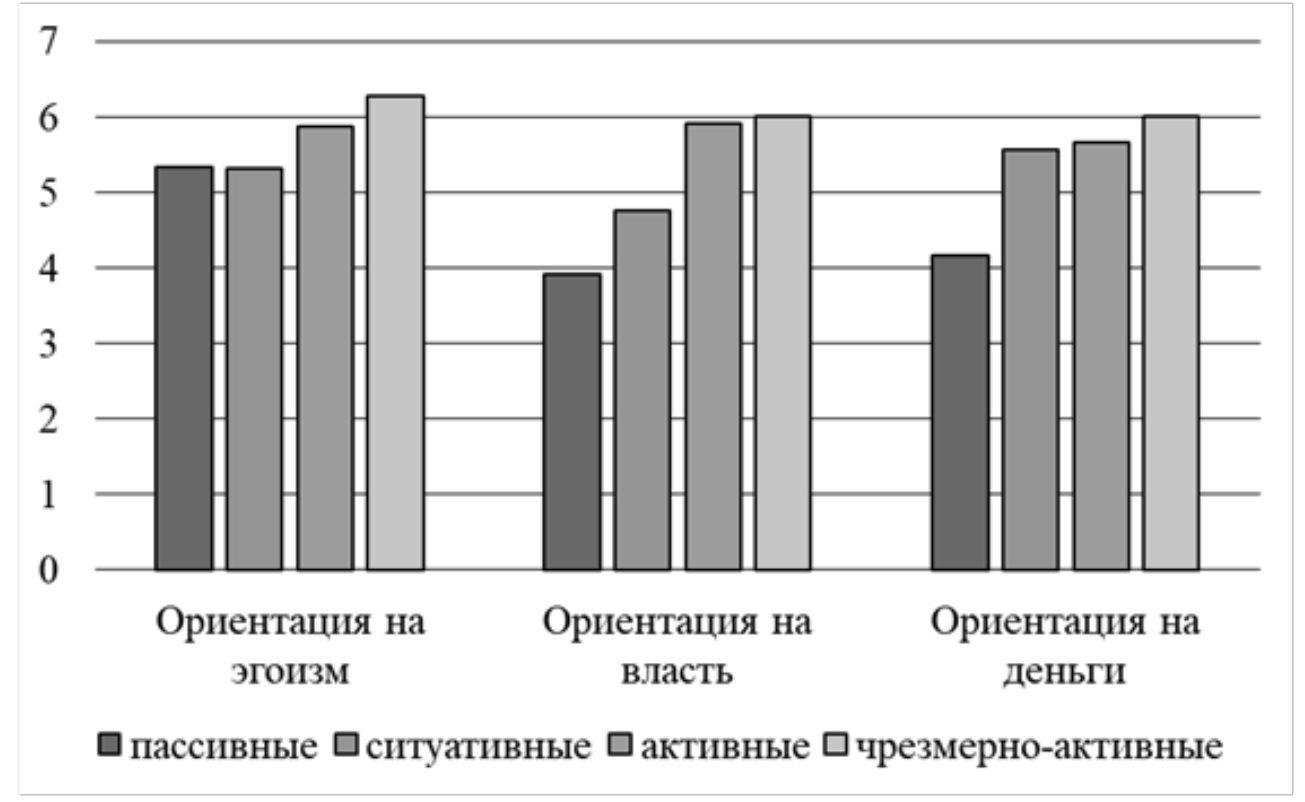

Рис. 2. Динамика шкал «Ориентация на эгоизм», «Ориентация на власть» и «Ориентация на деньги» при росте показателя интернет-активности

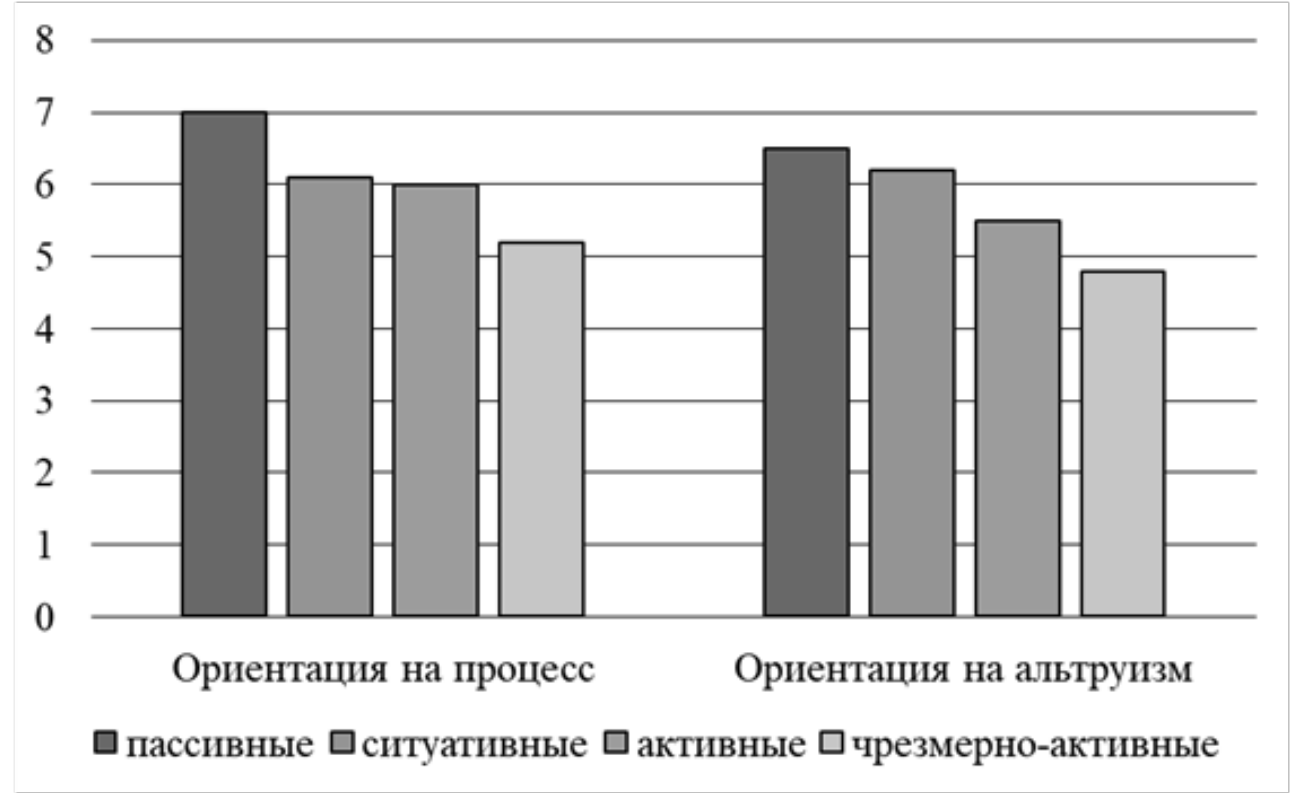

Рис. 3. Динамика шкал «Ориентация на процесс»

и «Ориентация на альтруизм» при росте показателя интернет-активности

которую нужно преодолеть. Такие испытуемые для обеспечения своей свободы готовы пренебрегать другими своими интересами, чтобы отстоять свою автономность.

Ориентация «На власть» отображает степень значимости власти, как социально-психологической установки. У респондентов с высокими показателями по данной шкале отмечается желание контроля над другими участниками процесса социального взаимодействия. Для таких испытуемых представляет ценность высокий статус и авторитет, позволяющие влиять на социум и других людей.

В ходе анализа результатов исследования было выявлено, что по мере роста уровня интернет-активности респондентов повышается выраженность ряда социально-психологических установок, таких как «Ориентация на эгоизм», «Ориентация на власть» и «Ориентация на деньги». Исходя из этого, можно отметить наличие зависимости между уровнем интернет-активности и данных компонентов ценностно-смысловой сферы личности. Таким образом, можно отметить, что с ростом уровня 


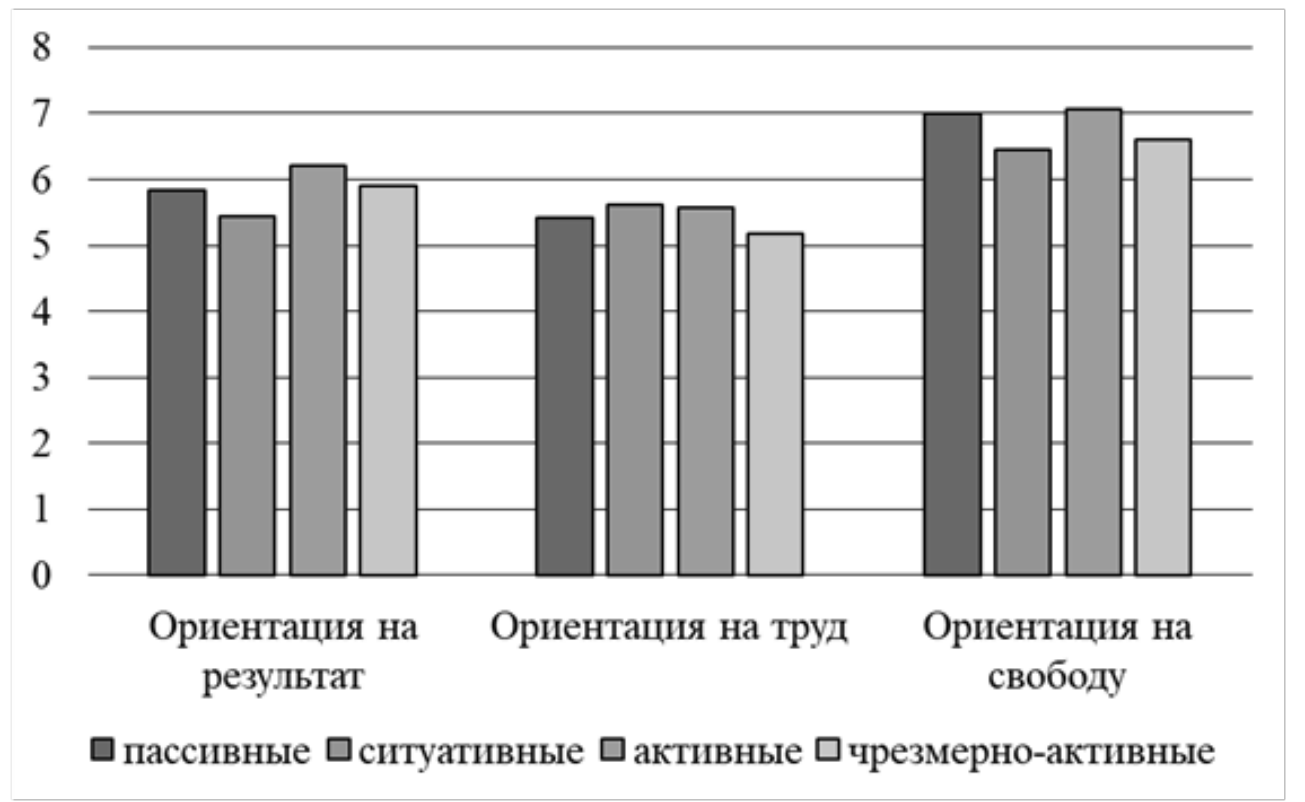

Рис 4. Динамика шкалы «» при росте показателя интернет-активности

интернет-активности у респондентов повышается желание достигать статуса для получения власти над другими людьми, повышать уровень собственного благосостояния и ориентироваться в первую очередь на собственные потребности и цели в ущерб другим участникам социального взаимодействия (рис. 2).

Также в ходе анализа результатов исследования было выявлено, что по мере роста уровня интернет-активности респондентов снижается выраженность ряда социально-психологических установок, таких как «Ориентация на процесс» и «Ориентация на альтруизм». Исходя из этого, можно отметить наличие зависимости между уровнем интернет-активности и данных компонентов ценностно-смысловой сферы личности. Таким образом, можно отметить, что с ростом уровня интернет-активности у респондентов снижается желание ориентироваться на процесс выполнения той или иной работы, а также нивелируется стремление оказывать помощь и поддержку другим участникам социального взаимодействия (рис. 3).

В ходе анализа результатов исследования также было выявлено, что по мере роста уровня интернет-активности респондентов неизменным остается выраженность ряда социально-психологических установок, таких как «Ориентация на результат», «Ориентация на труд» и «Ориентация на свободу». Исходя из этого, можно отметить отсутствие зависимости между уровнем интернетактивности и данных компонентов ценностно-смысловой сферы личности. Таким образом, можно отметить, что с ростом уровня интернет-активности у респондентов остается неизменным желание добиваться результата деятельности любыми путями, восприятие труда как ценности и стремление ощущать свободу и независимость в процессе общения с другими участниками социального взаимодействия (рис. 4).

\section{Выво $\Delta ы$.}

1. Ценностно-смысловая сфера личности представляет собой посреднический элемент между внутренним миром человека и социальной средой, которая его окружает. Ценностные и смысловые ориентации оказывают прямое влияние на развитие личности и выбор ею способов активности и деятельности.

2. Ценностно-смысловая сфера является комплексом характеристик, таких как субъективность (основанная на личном опыте), осознанность, комплексность, иерархичность и т.д. Эти свойства детерминируют особенности ее динамики с помощью ряда таких механизмов, как рефлексия, интернализация, экстернализация, индивидуализация, адаптация и т.д. При этом ценностно-смысловая сфера выступает в роли личностного конструкта, который определяет характер внутренних социокультурных ориентиров на определенный образ жизни.

3. С ростом уровня интернет-активности респондентов повышается выраженность ряда социальнопсихологических установок, таких как «Ориентация на эгоизм», «Ориентация на власть» и «Ориентация на деньги»; снижается значимость таких социально-психологических установок, таких как «Ориентация на процесс» и «Ориентация на альтруизм» и неизменным остается степень проявления ряда социально-психологических установок, таких как «Ориентация на результат», «Ориентация на труд» и «Ориентация на свободу». 


\section{ЛИТЕРАТУРА}

1. Алишев Б.С. Структура ценностного мира личности: фундаментальные ценности / Б.С. Алишев // Профессиональное образование. Казанский педагогический журнал. - 2000. - № 1. - С. 28-35.

2. Братусь Б.С. Аномалии развития личности / Б. С. Братусь. - Москва : Мысль, 1988. - 301 с.

3. Василюк Ф.Е. Психология переживания / Ф.Е. Василюк. - Москва : Издательство МГУ, 1984. - 200 с.

4. Васягина Н.Н. Человек как субъект социокультурного пространства / Н.Н. Васягина // Педагогическое образование в России. - 2013. - № 4. - С. 7-15.

5. Галажинский Э.В. Проблема уровней самореализации человека: ценностно-смысловой контекст / Э.В. Галажинский // Ценностные основания психологической науки и психология ценностей. / под ред. В. В. Знакова, Г. В. Залевского. - Москва : Институт психологии РАН, 2008. - С. 123-147.

6. Леонтьев Д.А. Методика предельных смыслов (методическое руководство) / Д.А. Леонтьев. - Москва : Смысл, 1999. - 38 с.

7. Лучинкина А.И. Специфика интернета как института социализации / А.И. Лучинкина // Научный результат. Педагогика и психология образования. - 2019. - №1. - C. 59-69.

8. Наумова Н.Г. Система ценностей человека как объект лингвистического исследования / Н.Г. Наумова // Вестник Нижегородского университета им. Н.И. Лобачевского. - 2016. - № 1. - С. 237-244.

9. Ольшанский В.Б. Личность и социальные ценности / В.Б. Ольшанский. - Москва: Просвещение, 1965. - 530 с.

10. Шерковин Ю.А. Проблема ценностных ориентаций и массовые информационные процессы / Ю.А. Шерковин // Психологический журнал. - 1982. - Т.3. №5. - С. 235-145.

11. Яницкий М.С. Ценностные ориентации личности как динамическая система / М.С. Яницкий. - Кемерово : Кузбассвузиздат, 2000. - 204 с.

\footnotetext{
(c) Зекерьяев Руслан Ильвисович (ruslan51291@mail.ru).
}

Журнал «Современная наука: актуальные проблемы теории и практики»

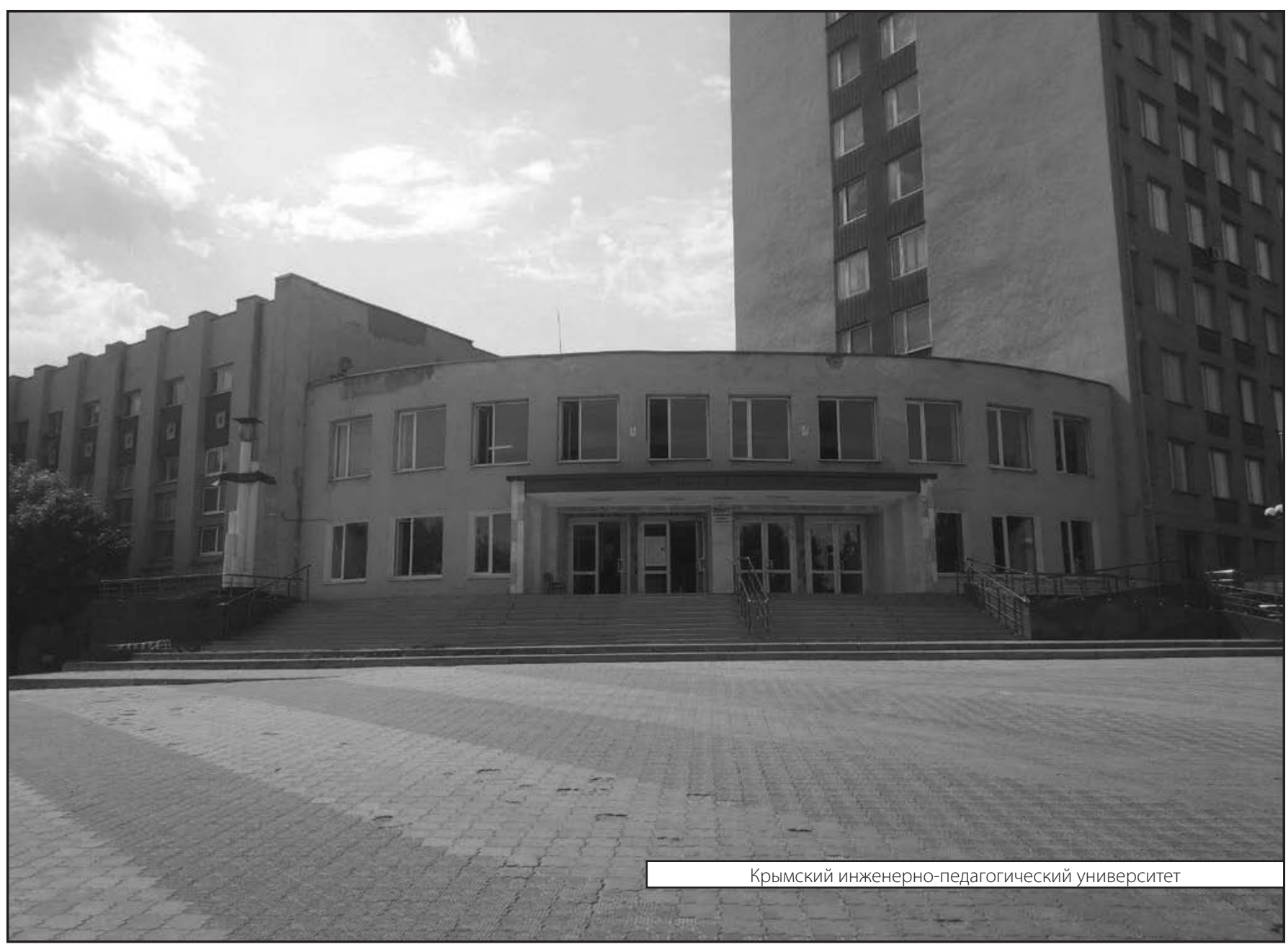

